Review Paper

\title{
Non-destructive testing technology for raw eggs freshness: a review
}

\author{
Liang $\mathrm{Qi}^{1,2,3} \cdot$ Mao-cheng Zhao ${ }^{1,2,4} \cdot$ Zhong $^{1} i^{1} \cdot$ De-hong Shen ${ }^{1} \cdot$ Jun $\mathrm{Lu}^{1,2}$
}

Received: 16 January 2020 / Accepted: 13 May 2020 / Published online: 22 May 2020

(c) Springer Nature Switzerland AG 2020

\begin{abstract}
Raw egg freshness indexes mainly include sensory indicators, air cell height, Haugh unit, pH value, yolk index, specific gravity of eggs and total volatile basic nitrogen content. Traditional methods can test only part samples with low efficiency. This paper reviews the application of visible/near infrared spectroscopy, machine vision, electronic nose, dielectric properties and low-field nuclear magnetic resonance (LF NMR) for new non-destructive testing of egg freshness. We analyze advantages and disadvantages of each technology, and focus on the application of LF NMR technique in this field. Finally, existing problems and future directions are proposed to provide useful information for further research.
\end{abstract}

\section{Graphic abstract}

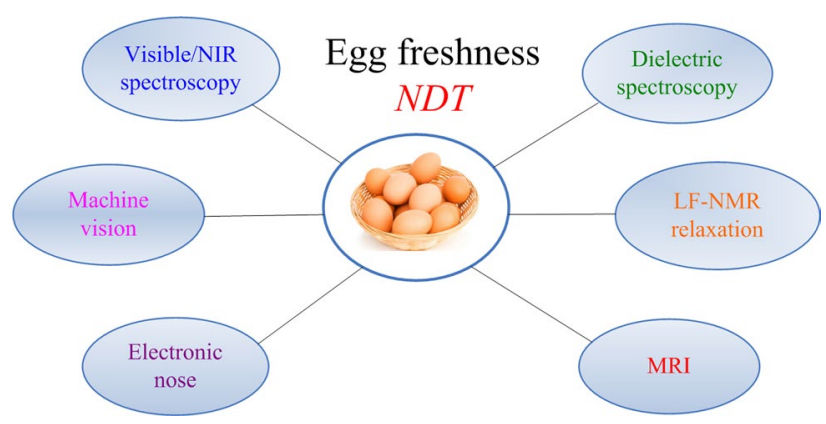

Keywords Raw eggs · Freshness · Non-destructive testing · Low-field nuclear magnetic resonance

JEL Classification L66

\section{Introduction}

Raw eggs with rich nutrition and edible convenience are the main variety of egg consumption and also important raw materials for food industry. Egg production in China has been increased, reaching 31.28 million tons in 2018 [5]. As fresh eggs come from livestock farms and farmers, production places are dispersed and purchase period is long.
While the peak season of laying eggs is in spring, summer and early autumn with high temperature, fresh eggs are easy to oxidize in sale, storage and logistics.

Egg deterioration refers to rotten eggs caused by decomposition of egg contents by microorganisms such as bacteria and molds in appropriate temperature and humidity conditions. Liquid in eggs laid by healthy poultry is sterile. Membrane over eggshells and albumen

$\triangle$ Mao-cheng Zhao, mczhao@njfu.edu.cn | ${ }^{1}$ National Engineering Research Center of Biomaterials, Nanjing Forestry University, Nanjing 210037, China. ${ }^{2}$ College of Mechanical and Electronic Engineering, Nanjing Forestry University, Nanjing 210037, China. ${ }^{3}$ Center for Analysis and Testing, Nanjing Normal University, Nanjing 210046, China. ${ }^{4}$ Taizhou University, Taizhou 225300, China. 
membrane close the stomata to prevent microorganism invasion. But, these defense systems are temporary and vulnerable to microbial reproduction and destruction, resulting in complex physical and chemical changes in eggs, including protein spoilage, fat rancidity and sugar decomposition. At present, there are several universal indexes of egg freshness, including sensory indicators, air cell height, Haugh unit, pH value, yolk index, specific gravity of eggs and total volatile basic nitrogen (TVBN) content. In China, we divide egg freshness into four grades: the super grade (AA), the first grade (A), the second grade (B) and the third grade (C) [33]. In Europe, the classes of quality classification are Class A-Extra fresh, Class A-category I and Class B [50]. And US grades are AA, A and B Quality [4]. The grade ranges of standards above are different.

Egg freshness testing methods can be divided into destructive testing technology and non-destructive testing (NDT) technology. Although its testing results are accurate and reliable, the destructive test is time-consuming. Besides, the tested samples are no longer can be eaten, and thus only part samples can be tested. NDT, with fast detection speed and no pretreatment of stripping eggshell, is suitable for on-line detection. This paper listed traditional testing methods and NDT methods for freshness indexes, focused on existing problems of LF NMR application in this field and discussed methods of further study.

\section{Freshness indexes and traditional testing methods}

\subsection{Sensory indicators}

Sensory indicators include color, odor and state [35]. By visual inspection, inspectors observe the color and mildew of egg before the candling light and the color of yolk and albumen after being broken out. Inspectors also detect the odor of egg liquid by olfaction. This method is fast and simple without limitation of test conditions. However, it asks for a high need for inspectors' ability and the results remain defects of subjectivity or one-sidedness.

\subsection{Air cell height}

Air cell is formed between albumen membrane and shell inner membrane at the blunt end of an egg. Air cell enlarges continuously during storage, as water evaporates through the stomata on the eggshell and thus air cell height can reflect egg freshness. According to Chinese regulations, which puts forward high requirements for detection accuracy, heights of super, first, second and third grade are less than $4 \mathrm{~mm}, 6 \mathrm{~mm}, 8 \mathrm{~mm}$ and $9.5 \mathrm{~mm}$, respectively [33]. Stomata on the eggshell make egg transparent. Thus, air cell height can be observed with a graduated transparent plastic sheet when eggs are illuminated by light.

\subsection{Haugh unit}

Egg albumen can be divided into two types, thin albumen and thick albumen, based on their morphology. Thick albumen is gradually hydrolyzed during storage. When a fresh egg and a stale egg are broken and the contents are poured on a horizontal glass surface, we can see that the thick albumen of the fresh egg evenly adheres to the yolk, while the thick albumen of the stale egg is rare, almost all thin albumen. So, the height of thick albumen can be measured by a vertical micrometer to calculate Haugh unit (HU) as shown in Formula (1) [40]:

$H U=100 \lg \left(H-1.7 m^{0.37}+7.57\right)$

where $\mathrm{HU}$ is the Haugh unit; $\mathrm{H}$ is the height of thick albumen $(\mathrm{mm}) ; \mathrm{m}$ is the weight of egg $(\mathrm{g})$.

In China, the HU of AA quality is above 72; The HU of A quality is between 60 and 72 ; The $\mathrm{HU}$ of $B$ quality is between 31 and 59; The $\mathrm{HU}$ of $C$ quality is below 31 [33]. The 3 grades in the US, is above $72(\mathrm{AA})$, between 60 and $72(A)$, below $60(B)$.

\section{$2.4 \mathrm{pH}$ value}

$\mathrm{pH}$ value of albumen in a fresh egg is between 7.6 and 7.9. $\mathrm{pH}$ value gradually increases to $9.0-9.7$, as $\mathrm{CO}_{2}$ diffuses from an egg into air through stomata during storage [24, 44]. Longer periods of storage resulted in higher albumen $\mathrm{pH}$ [38]. The greatest change in $\mathrm{pH}$ occurred during the beginning several days, and then the $\mathrm{pH}$ changed slowly $[18,41]$. Because the change of yolk's $p H$ value is not obvious, egg freshness is usually judged by albumen $\mathrm{pH}$ value measured by $\mathrm{pH}$ meter [16].

\subsection{Yolk index}

Fresh yolk is raised after being poured on a horizontal glass surface, while stale yolk is flat. There are two main reasons: (1) fat and protein in yolk gradually hydrolyze during storage, which causes the decrease of yolk viscosity; (2) the yolk is wrapped by a permeable yolk membrane, and salt concentration of yolk is higher than albumen, which forms osmotic pressure between them. Salt in yolk permeates into albumen, and water of albumen permeates yolk. The longer an egg is stored, the longer penetration lasts, eventually leading to scattered yolk. Therefore, the yolk index (YI) can express egg freshness, as shown in Formula (2) [48]: 
$Y I=H / W$

where $Y I$ is the yolk index; $H$ is the height of yolk $(\mathrm{mm})$, which is measured by vertical micrometer; $W$ is the diameter of yolk ( $\mathrm{mm}$ ) measured by vernier caliper.

It can be concluded that the staler the egg is, the smaller the $\mathrm{Yl}$ is. The $\mathrm{YI}$ of fresh egg ranges from 0.3 to 0.5 with a mean value of $0.42[13,14]$. When $\mathrm{Yl}$ is less than 0.25 , loose yolk appears [24].

\subsection{Specific gravity}

In an egg, water evaporates and albumen become thinner during storage, so specific gravity of an egg decreases gradually, which can be measured to get freshness. It is determined by salt water floatation method: $68 \mathrm{~g} \mathrm{NaCl}$ is added into $1000 \mathrm{ml}$ water, which is determined as level 0 . Adding 1 grade, another $4 \mathrm{~g} \mathrm{NaCl}$ is added, totaling 9 grades. Starting from Grade 0 , an egg is put into the brine step by step, and the least brine specific gravity of a drifted egg is freshness level [32]; a fresh egg is classified as above Grade 3 [24].

\subsection{Total volatile basic nitrogen}

Albumen is decomposed by enzymes and bacteria to produce ammonia and amine alkaline substances, which are volatile and known as total volatile basic nitrogen (TVBN). The higher TVBN value is, the staler the egg is [45]. The commonly used determination methods are semi-micro distillation method in Kjeldahl nitrogen analyzer [51].

\subsection{Comparison of indexes}

Each freshness index reflects the change of egg freshness. Table 1 compares freshness indexes from test methods, tightness with freshness, convenience, accuracy, and so on. Sensory indicators, air cell height and $\mathrm{HU}$ are used for freshness evaluation $[4,33,50]$. Sensory indicators are suitable for rough examination of freshness, because they are susceptible to subjective factors of examiners. Air cell height and $\mathrm{HU}$ are accurate and credible, so they are the main basis for egg grading. However, measurement accuracy of air cell height and $\mathrm{HU}$ relies on the manual measurement level of testers. Besides, $\mathrm{HU}$ is obtained by destructive detection, which is difficult to achieve fullcoverage test or online detection, so more and more researches focus on NDT method for egg freshness.

\section{NDT methods for egg freshness}

NDT, which can quickly get freshness value by on-line and full inspection without destroying samples, has been widely used in egg freshness detection. NDT is of great significance to quality grade, pricing, and supervision of egg production and sale.

\subsection{Visible/near infrared spectroscopy}

The eggshell has dense stomata with an aperture of 4-40 $\mu \mathrm{m}$ and has good light transmittance. The chemical constituents related to egg freshness were characterized in visible and near-infrared spectra. Spectral analysis technology can realize freshness nondestructive detection. Spectral data are usually collected by transmission mode. Abdanan Mehdizadeh et al. [1] got 400-1100 nm spectra of eggs, used Fast Fourier transform (FFT) pre-processing algorithm and Genetic algorithm-Back propagation neuronal network (GA-BPNN) model to predict freshness with accuracy of $94 \%$. It was also found that the transmission of light along the egg poles has a better spectral signal-tonoise ratio than that along the equator. Aboonajmi et al. [2] used principal component analysis (PCA) and radial basis function network to establish models for predicting $\mathrm{HU}$ and the height of an air cell in 300-1100 $\mathrm{nm}$ band. Dong et al. [10] proved that albumen $\mathrm{pH}$ prediction model based on $550-850 \mathrm{~nm}$ spectra was superior to the whole

Table 1 Comparison of egg freshness attributes

\begin{tabular}{|c|c|c|c|c|c|c|c|c|}
\hline Index name & $\begin{array}{l}\text { Included in } \\
\text { US Stand- } \\
\text { ard }\end{array}$ & $\begin{array}{l}\text { Included in } \\
\text { EU Stand- } \\
\text { ard }\end{array}$ & $\begin{array}{l}\text { Included in } \\
\text { China Stand- } \\
\text { ard }\end{array}$ & $\begin{array}{l}\text { Destructive or } \\
\text { non-destructive }\end{array}$ & Testing methods & Testing speed & $\begin{array}{l}\text { Correspond- } \\
\text { ence with } \\
\text { freshness }\end{array}$ & $\overline{\text { Accuracy }}$ \\
\hline Sensory & Yes & Yes & Yes & Destructive & Physical & Fast & General & Poor \\
\hline Air cell height & Yes & Yes & Yes & Non-destructive & Physical & General & Tight & Accurate \\
\hline $\mathrm{HU}$ & Yes & No & Yes & Destructive & Physical & General & Tight & Accurate \\
\hline $\mathrm{pH}$ & No & No & No & Destructive & Physical & General & Tight & Accurate \\
\hline $\mathrm{YI}$ & No & No & No & Destructive & Physical & General & Tight & Accurate \\
\hline Specific gravity & No & No & Yes & Non-destructive & Physical & Fast & Tight & General \\
\hline TVBN & No & No & No & Destructive & Chemical & Slow & Tight & Accurate \\
\hline
\end{tabular}


egg $\mathrm{pH}$ prediction model. Duan et al. [11] established a non-linear HU prediction model (550-950 $\mathrm{nm}$ ) based on local linear embedding (LLE) and support vector regression (SVR) algorithm. Prediction accuracy of non-linear models was better than linear ones, which proved that the non-linear relationship exists between spectral data and freshness-related chemicals.

Eggshell color can disturb spectral data, which results in model differences. Dong et al. [9] studied calibration model transfer between White Leghorn eggs and Bantam eggs for prediction of albumen $\mathrm{pH}$ by partial least squares regression (PLSR). This transfer technology could be applied to predict egg freshness of a new variety without extra model building. Besides, the feasibility of predicting freshness by visible/near infrared spectroscopy has been proved by the optimization of spectral band, modeling algorithm and freshness indicators $[7,15,25]$.

\subsection{Machine vision}

Eggshells are transparent. Air cell size and ellipticity of yolk can be observed by transmission light and prediction models of freshness indexes based on machine vision are established $[23,25,30]$. This technology can achieve on-line and full inspection of egg freshness. At present, mature commercial detection schemes are available $[34,37]$. Soltani et al. [43] designed a device combining machine vision with dielectric constant detection and established a multi-source data fusion model to predict egg freshness. Hyperspectral image analysis technology can not only reflect image information of samples and machine vision but also reflect spectral information of each pixel in the image. Its freshness information can be observed more clearly in high dimension of multi-band spectra, such as scattered yolk detection (spectral band: 380-1010 nm) [53] and analysis of spatial distribution information of egg freshness in image (spectral band: 900-1700 nm) [46].

\subsection{Electronic nose}

Gas sensors named electronic noses can collect deteriorating gas during egg spoiling, such as ammonia oxides, alkanes and alcohols. The sensors' data distinguish egg freshness grade with the help of pattern recognition algorithms [28]. Li et al. [20] distinguished eggs stored for different days through linear discriminant analysis (LDA) method, whose correlation coefficient was 0.84 . Li et al. [21] used wavelet energy analysis to process data from electronic nose, and evaluated storage time and yolk index. Liu and Tu [29] predicted TVBN content in an egg by an SVR model. Deng et al. [8] made a comparative study of gas sensor materials' sensibility to freshness changing.

\subsection{Dielectric spectroscopy}

Generally, an egg contains $73 \%$ water, $13 \%$ hydrated protein and trace $\mathrm{Na}^{+}$and $\mathrm{K}^{+}$ions, with conductivity characteristics. Component deterioration in eggs will change their dielectric spectroscopy.[48]used two parallel plates to measure the dielectric spectroscopy of eggs with different freshness grades at a frequent band of $1-200 \mathrm{kHz}$, and found that dielectric parameters decreased with the increase of frequency and YI. Soltani and Omid [42] designed an electronic device based on dielectric technique operated at radio frequencies $0.04-20 \mathrm{MHz}$, which collected data into computers within just $700 \mathrm{~ms}$. Some machine learning methods, such as artificial neural networks (ANN), support vector machines (SVMs), decision trees (DTs) and Bayesian networks (BNs), were used to establish classification models of egg freshness, with good predictive performance. Lau and Subbiah [19] developed a high-frequency system (10-3000 MHz) for an automatic dielectric test of yolk, albumen, and a whole egg. It had been proved that freshness has a great influence on egg dielectric properties, except temperature and frequency. Akbarzadeh et al. [3] constructed a high frequency waveguide device $(0.9-1.7 \mathrm{GHz})$ to get high-frequency dielectric properties of eggs in transmission and reflection modes. An optimal ANN model was built to predict $\mathrm{Yl}$, air cell height, $\mathrm{HU}$ and $\mathrm{pH}$ value of albumen.

\subsection{Low-field nuclear magnetic resonance}

Compared with high-field nuclear magnetic resonance, low-field nuclear magnetic resonance (LF NMR) testing equipment adopts permanent magnet structure, without complex cooling device and shield, which reduces the size and cost of equipments. LF NMR technology is widely used in food field to determine quality by measuring relaxation characteristics and describing magnetic resonance imaging (MRI) of different components (water, protein or oil) in food $[26,36,39,49]$. This NDT application can help realize dynamic monitoring of food processes and production. LF NMR analysis technology mainly includes two aspects, relaxation spectrum analysis technology and MRI analysis technology.

Spin space orientation of the ${ }^{1} \mathrm{H}$ nuclei in water molecules transits from disorder to order and reaches thermal equilibrium state after applying to an external magnetic field, and magnetization vector is in equilibrium position. When the spin system is affected by external radio frequency (RF) field, magnetization vector deviates from equilibrium position. When RF field stops, spin system 
returns to equilibrium. This process is called relaxation process, which can be divided into two types:

- Spin-lattice relaxation is also known as longitudinal relaxation. Half-life of relaxation process is expressed $\mathrm{T}_{1}$.

- Spin-spin relaxation is also known as transverse relaxation, whose half-life is expressed as $T_{2}$.

These relaxation signals need to be inverted to get signal intensity of each component at different relaxation time, which is related to component information. The research mainly concentrated on the influence of water content on food, such as meat taste [36], and internal water content change during food drying [22], and also focused on oil detection, such as oil variety monitoring [31], oil and water content determination in fried starch food [6].

If a gradient magnetic field applies to a sample, nuclear spin in the only one narrow layer is excited, and relaxation signals within this layer can be received to form MRI. Like the means of medical MRI analysis, the shape and size of the target object are analyzed by in situ detection and image processing technology to determine sample quality, such as flesh change of fresh Jujube during storage [47], internal moisture state of sea cucumber during rehydration process [54].

Laghi et al. [17] studied relaxation signals of eggs related to freshness, predicted the feasibility of egg freshness NDT by MRI, and analyzed the reason for relaxation signal change during storage, because the increased albumen $\mathrm{pH}$ value leads to changes of spin environment of ${ }^{1} \mathrm{H}$ protons. But the inversion spectra of relaxation signals were not calculated. The samples only covered storage time at $\mathrm{d} 0$ and $\mathrm{d} 7$, with no other spoiling period. Because of weak instrument performance, the relaxation signal had a low temporal resolution, and it was hard to observe relaxation characteristics of protein hydrolysis process related to freshness. Lin et al. [27] studied egg spoilage by LF NMR and MRI. It was found that the relaxation characteristics are significantly correlated with freshness indexes, such as storage time, air cell height, $\mathrm{Yl}$ and HU. However, the predictive model was not established. The inner structure of an egg was observed by MRI, and the gradually increased air cell in metamorphic process was shown. Unfortunately, this MRI did not use situ technique, and yolk outline was not clear enough. Xu et al. [52] studied the significant correlation between relaxation signals of albumen and freshness indexes. It was proved that $\mathrm{CO}_{2}$ modified atmosphere storage could restrain the decline of water-protein combination capacity and boost the dynamic characteristics of free water, which could be expressed by relaxation signals, but the pretreatment of albumen separation was destructive. Duan et al. [12] pointed out that relaxation signals interrelate with moisture loss and oxidization of boiled eggs, but there was no raw sample.

It can be concluded that the LF NMR NDT for egg freshness, including relaxation spectral analysis and MRI analysis, has not been fully studied.

\subsection{Research assumption for LF NMR}

Albumen gradually hydrolyzes as freshness decreases. Water and $\mathrm{CO}_{2}$ in an egg also gradually dissipate through stomata. These changes are reflected in the relaxation signals $T_{1}$ and $T_{2}$, and can be observed through $T_{1}$ or $T_{2}$ spectra after inversion. We can get changes of substances related to freshness in samples and realize LF NMR test of freshness, by analyzing spectra and establishing chemometric models of relationship between spectral data and freshness indexes. We need sufficient samples and suitable models, which is important for future research.

Several raw eggs were stored for 42 days in a constant temperature box at $25^{\circ} \mathrm{C}$ and $60 \%$ humidity. The experimental data of an optional egg was displayed in this paper. $\mathrm{T}_{1}$ and $\mathrm{T}_{2}$ relaxation spectra were shown in Fig. 1. Peaks in spectra corresponding to freshness components need to be further identified through experiments.

As shown in Fig. 2, yolk contour and outline of air cell can be seen in MRI for the differences in components and relaxation signal energy. Similar to the NDT method of machine vision, an MRI NDT model for predicting freshness can be established by observing the size and shape of the air cell and yolk. Compared with machine vision and visible/near infrared spectroscopy, MRI technology is more compatible without the interference of eggshell color and pollutants on the surface.

LF NMR tested 9 raw eggs with different freshness. The size of air cell and yolk were collected from MRI without being broken out. Then, their HU values were tested after being broken out. These data established an MRI NDT model for predicting freshness. Figure 3 is the scatter plot between measured HU values and NDT model predicted results. The accuracy of prediction shows further research is needed, including more samples and more accurate prediction model, which are our study directions.

\section{Conclusion}

Egg freshness indexes include sensory, air cell height and HU. Compared with meat and vegetables, it is difficult to judge egg freshness without removing the opaque shell which increases the difficulty of quality control in production and distribution. Although the destructive detection methods have high accuracy, they are time consuming because of complex operation. NDT methods are fast and 

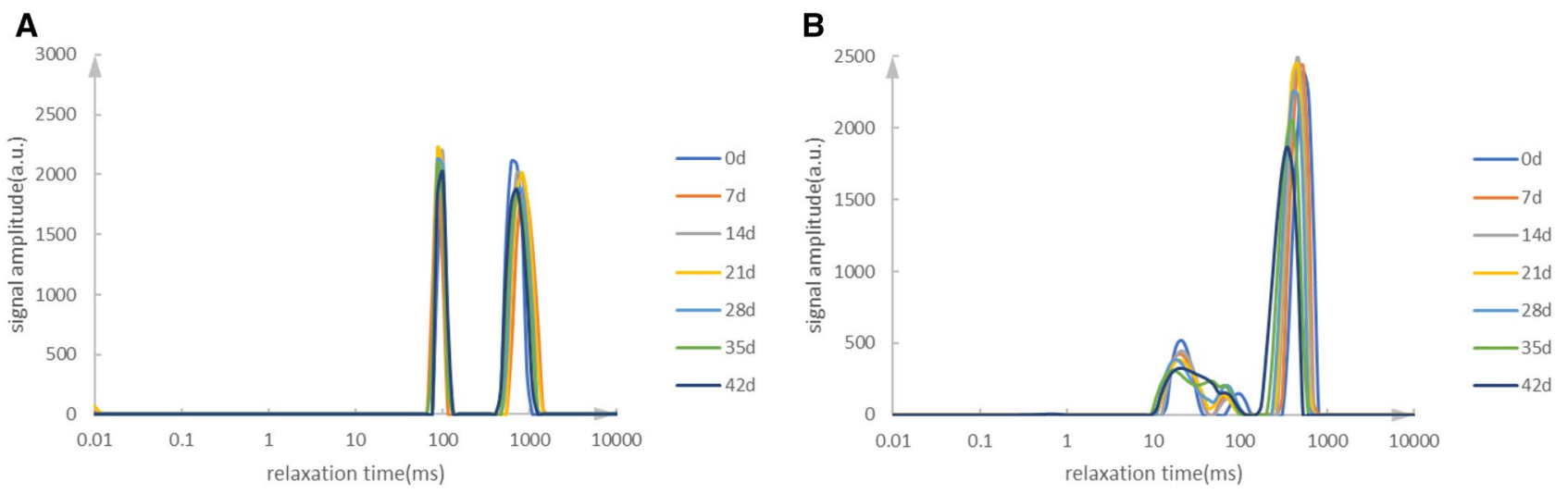

Fig. 1 Relaxation spectra of a raw egg: $\mathbf{a} \mathrm{T}_{1}$ spectra, $\mathbf{b} \mathrm{T}_{2}$ spectra

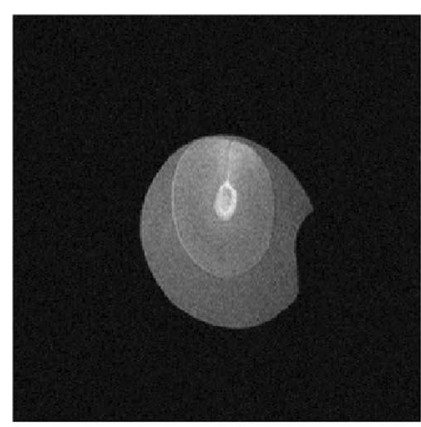

Od

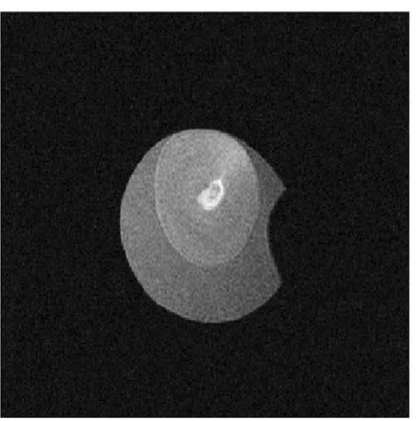

$7 d$

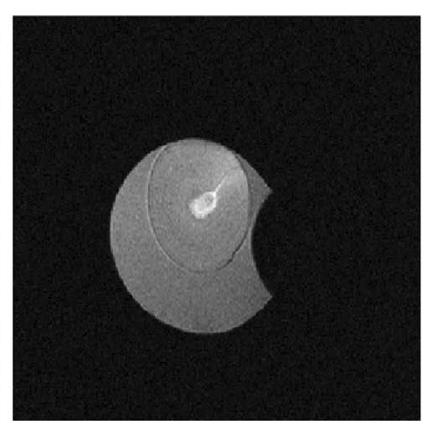

$14 d$

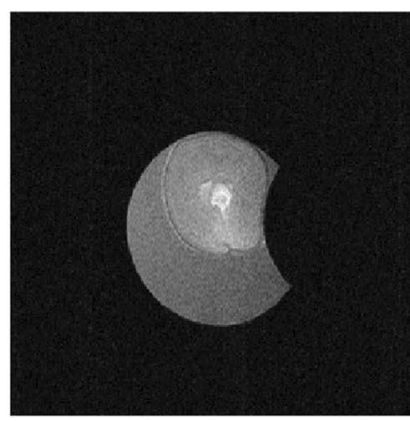

21d

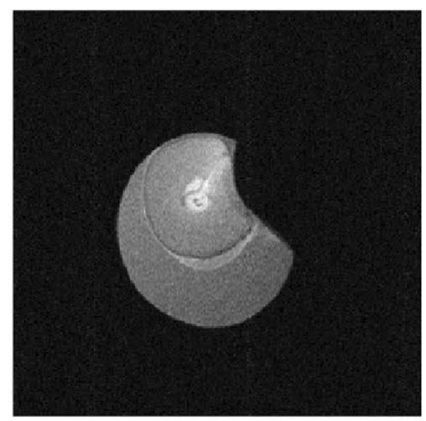

$28 d$

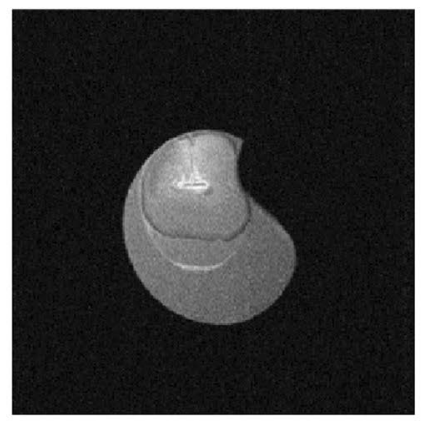

$35 d$

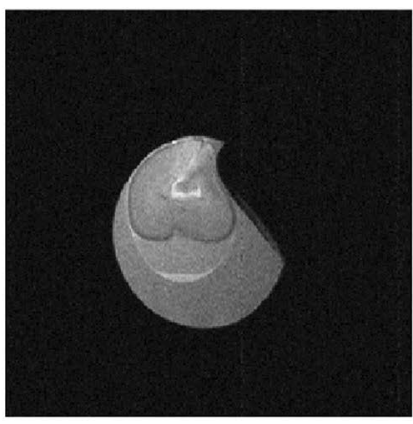

$42 d$

Fig. 2 MRI of a raw egg. With the increase of storage time, the area of air cell was increasing (right side of the egg contour), the oval shape of the yolk edge was losing, and water of albumen was permeating into the yolk

easy to operate with no damage to the egg, which can achieve online detection. NDT technologies and accuracy have improved. The advantages and disadvantages of NDT techniques above are shown in Table 2.
Researches of LF NMR for egg freshness started late and are not thorough. It is workable to detect egg freshness by relaxation spectroscopy and MRI analysis technology. These two data sources can be further fused to establish a more accurate NDT model. It is significant to develop LF NMR NDT equipment for rapid detection of egg quality. 


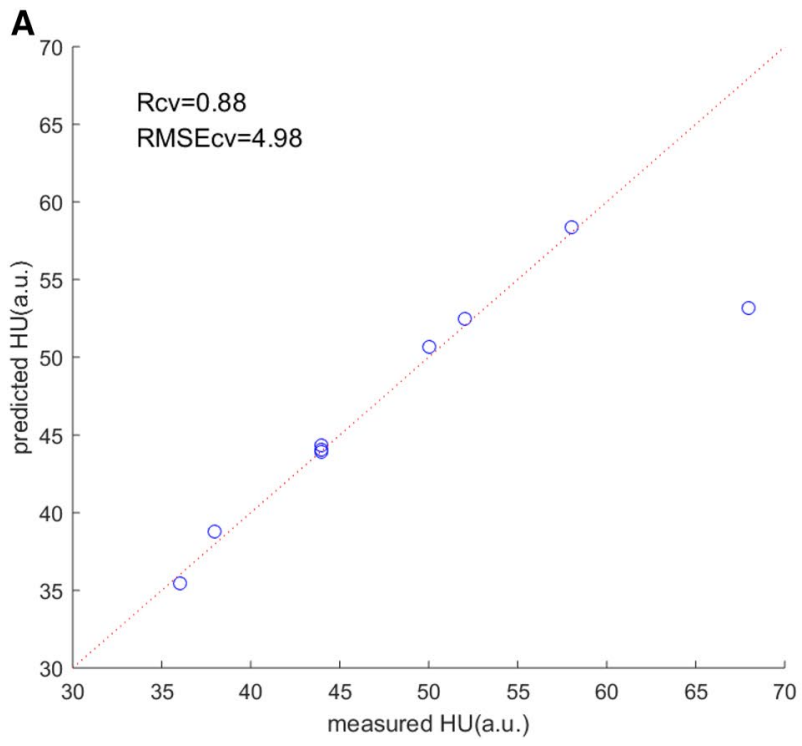

Fig. 3 Relationship between the measured and predicted $\mathrm{HU}$ : a all samples, $\mathbf{b}$ the outlier was removed. An MRI NDT model for predicting $\mathrm{HU}$ was established by leave-one-out cross validation (LOOCV) and back propagation artificial neural network (BPANN) upon MRI data (size of air cell and yolk) and measured HU. There was a sam-

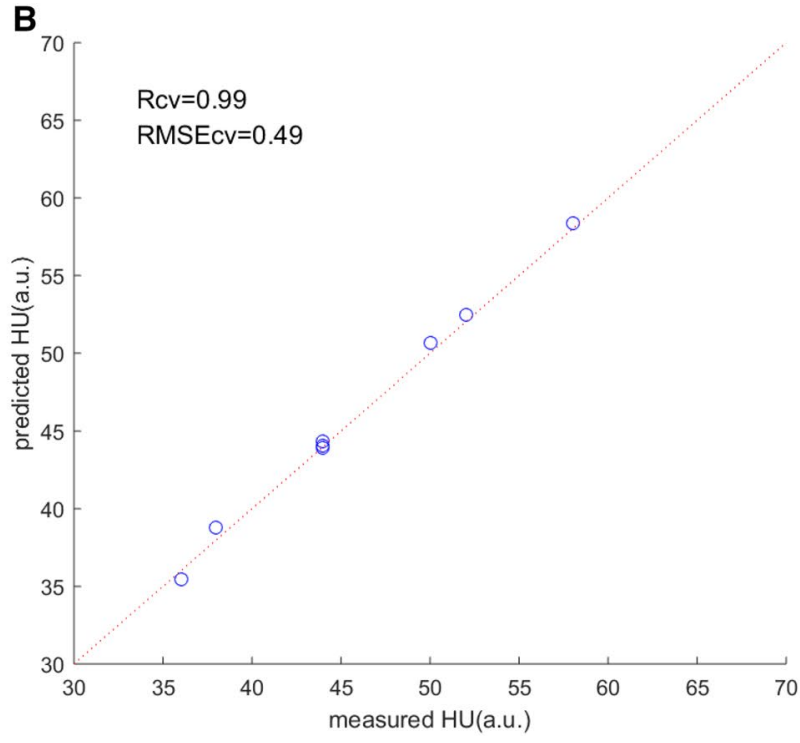

ple away from the $45^{\circ}$ line. It may be caused by errors in the manual measurement of HU. The sample couldn't be used for analysis. So it was removed and the model's root mean square error of prediction $\left(R M S E_{C V}\right)$ and correlation coefficient $\left(R_{C V}\right)$ were 0.49 and 0.99 respectively

Table 2 Analysis of advantages and disadvantages of NDT technologies

\begin{tabular}{|c|c|c|}
\hline NDT methods & Advantages & Disadvantages \\
\hline $\begin{array}{l}\text { Visible/near infrared } \\
\text { spectroscopy }\end{array}$ & Fast, strong anti-interference and moderate cost & $\begin{array}{l}\text { Affected by eggshell color, surface pollutants and detec- } \\
\text { tion position }\end{array}$ \\
\hline Machine vision & $\begin{array}{l}\text { High definition, intuitive results, fast, strong anti-interfer- } \\
\text { ence, moderate cost }\end{array}$ & Affected by eggshell color and surface pollutants \\
\hline Electronic nose & $\begin{array}{l}\text { Not affected by eggshell color or surface pollutants, low } \\
\text { cost }\end{array}$ & $\begin{array}{l}\text { Closed collection environment, long stable period of time, } \\
\text { slow }\end{array}$ \\
\hline Dielectric properties & Simple design, low cost and fast & Affected by temperature and humidity, low stability \\
\hline LF NMR & $\begin{array}{l}\text { Intuitive results, not affected by eggshell and environ- } \\
\text { mental factors }\end{array}$ & $\begin{array}{l}\text { More cost, online transmission devices need non-metallic } \\
\text { materials }\end{array}$ \\
\hline
\end{tabular}

Funding This study was funded by China Scholarship Council (Grant Number 201906865020).

\section{Compliance with ethical standards}

Conflict of interest The authors declare that they have no conflict of interest.

\section{References}

1. Abdanan Mehdizadeh S, Minaei S, Hancock NH, Karimi Torshizi MA (2014) An intelligent system for egg quality classification based on visible-infrared transmittance spectroscopy.
Inf Process Agric 1(2):105-114. https://doi.org/10.1016/j. inpa.2014.10.002

2. Aboonajmi M, Saberi A, Abbasian Najafabadi T, Kondo N (2016) Quality assessment of poultry egg based on visible-near infrared spectroscopy and radial basis function networks. Int J Food Prop 19(5):1163-1172. https://doi.org/10.1080/10942 912.2015.1075215

3. Akbarzadeh N, Mireei SA, Askari G, Mahdavi AH (2019) Microwave spectroscopy based on the waveguide technique for the nondestructive freshness evaluation of egg. Food Chem 277:558-565. https://doi.org/10.1016/j.foodchem.2018.10.143

4. AMS (2000) United States standards, grades, and weight classes for shell eggs. USDA, Washington

5. CEIDB (2019) Production of agricultural products in china (eggs). China economic network data Co., Ltd, Beijing

6. Chen L, Tian YQ, Sun BH, Wang JP, Tong QY et al (2017) Rapid, accurate, and simultaneous measurement of water and oil contents in the fried starchy system using low-field NMR. 
Food Chem 233:525-529. https://doi.org/10.1016/j.foodc hem.2017.04.147

7. Coronel-Reyes J, Ramirez-Morales I, Fernandez-Blanco E, Rivero D, Pazos A (2018) Determination of egg storage time at room temperature using a low-cost NIR spectrometer and machine learning techniques. Comput Electron Agric 145:110. https://doi.org/10.1016/j.compag.2017.12.030

8. Deng FF, Chen W, Wang J, Wei ZB (2018) Fabrication of a sensor array based on quartz crystal microbalance and the application in egg shelf life evaluation. Sens Actuators B Chem 265:394-402. https://doi.org/10.1016/j.snb.2018.03.010

9. Dong XG, Dong J, Li YL, Xu HB, Tang XY (2019) Maintaining the predictive abilities of egg freshness models on new variety based on VIS-NIR spectroscopy technique. Comput Electron Agric 156:669-676. https://doi.org/10.1016/j.compa g.2018.12.012

10. Dong XG, Dong J, Peng YK, Tang XY (2017) Comparative study of albumen $\mathrm{pH}$ and whole egg $\mathrm{pH}$ for the evaluation of egg freshness. Spectrosc Lett 50(9):463-469. https://doi. org/10.1080/00387010.2017.1360357

11. Duan YF, Wang QH, Ma MH, Lu X, Wang CY (2016) Study on non-destructive detection method for egg freshness based on LLE-SVR and visible/near-infrared spectrum. Guang Pu Xue Yu Guang Pu Fen Xi/Spectrosc Spectr Anal 36(4):981-985. https:// doi.org/10.3964/j.issn.1000-0593(2016)04-0981-05 (in Chinese)

12. Duan YX, Zhao Y, Chi YJ (2018) Low field nuclear magnetic resonance analysis of moisture distribution and quality variation in boiled eggs under different storage conditions. Shipin Kexue/ Food Sci 39(9):26-32. https://doi.org/10.7506/spkx1002-6630201809005 (in Chinese)

13. Eke MO, Olaitan NI, Ochefu JH (2013) Effect of storage conditions on the quality attributes of shell (table) eggs. Niger Food J 31(2):18-24. https://doi.org/10.1016/S0189-7241(15)30072-2

14. Ihekoronye PO, Ngoddy Al (1985) Integrated food science and technology for tropics. Macmillan Press, London

15. Jie DF, Wang XJ, Wei X (2016) Research on the detection model of egg freshness based on the near-infrared spectroscopy technology. Food Mach 32(8):115-118. https://doi.org/10.13652/j.i ssn.1003-5788.2016.08.028 (in Chinese)

16. Kirunda DF, McKee SR (2000) Relating quality characteristics of aged eggs and fresh eggs to vitelline membrane strength as determined by a texture analyzer. Poult Sci 79(8):1189-1193. https://doi.org/10.1093/ps/79.8.1189

17. Laghi L, Cremonini MA, Placucci G, Sykora S, Wright $\mathrm{K}$ et al (2005) A proton NMR relaxation study of hen egg quality. Magn Reson Imaging 23(3):501-510. https://doi.org/10.1016/j. mri.2004.12.003

18. Lapao C, Gama LT, Soares MC (1999) Effects of broiler breeder age and length of egg storage on albumen characteristics and hatchability. Poult Sci 78(5):640-645. https://doi.org/10.1093/ $\mathrm{ps} / 78.5 .640$

19. Lau SK, Subbiah J (2018) An automatic system for measuring dielectric properties of foods: Albumen, yolk, and shell of fresh eggs. J Food Eng 223:79-90. https://doi.org/10.1016/j.jfood eng.2017.11.039

20. Li JT, Wang J, Li Y, Wei Y (2017) Detection of egg freshness using electronic nose. Modern Food Sci Technol 33(4):300-305. https ://doi.org/10.13982/j.mfst.1673-9078.2017.4.046 (in Chinese)

21. Li JT, Zhu SS, Jiang S, Wang J (2017) Prediction of egg storage time and yolk index based on electronic nose combined with chemometric methods. LWT Food Sci Technol 82:369-376. https ://doi.org/10.1016/j.lwt.2017.04.070

22. Li N, Li (2016) Analysis of internal moisture changes of Benincasa hispida during vacuum drying using low-field NMR. Shipin
Kexue/Food Sci 37(23):84-88. https://doi.org/10.7506/spkx1 002-6630-201623014 (in Chinese)

23. Li XC, Zhao DL, Shi HL, Yun YL (2019) Non-destructive testing method of egg quality based on machine vision. J Food Saf Qual 10(2):489-493. https://doi.org/10.3969/j.issn.20950381.2019.02.034 (in Chinese)

24. Li XD (2005) Egg science and technology. Chemical Industry Press, Beijing, pp 47-50 (in Chinese)

25. Lin H, Zhao JW, Sun L, Chen QS, Zhou F (2011) Freshness measurement of eggs using near infrared (NIR) spectroscopy and multivariate data analysis. Innov Food Sci Emerg Technol 12(2):182-186. https://doi.org/10.1016/j.ifset.2011.01.008

26. Lin SY, Yang SL, Li XF, Chen F, Zhang MD (2016) Dynamics of water mobility and distribution in soybean antioxidant peptide powders monitored by LF-NMR. Food Chem 199:280-286. https ://doi.org/10.1016/j.foodchem.2015.12.024

27. Lin XY, Jin ZQ, Zhu RB, Zhang JS, Liu YH et al (2009) Studies on the decay process of egg by NMR and MRI. J Chin Inst Food Sci Technol 9(2):126-131. https://doi.org/10.3969/j.issn.10097848.2009.02.022 (in Chinese)

28. Liu M, Pan LQ, Tu K, Liu P (2010) Determination of egg freshness during shelf life with electronic nose. Nongye Gongcheng Xuebao/Trans Chin Soc Agric Eng 26(4):317-321. https://doi. org/10.3969/j.issn.1002-6819.2010.04.054 (in Chinese)

29. Liu P, Tu K (2012) Prediction of TVB-N content in eggs based on electronic nose. Food Control 23(1):177-183. https://doi. org/10.1016/j.foodcont.2011.07.006

30. Liu Y, Li QW, Huang XW, Huo GY, Zhou Y (2015) Egg characteristics extraction from light transmission image and egg freshness model training. Sci Technol Eng 15(25):72-77. https://doi. org/10.3969/j.issn.1671-1815.2015.25.013 (in Chinese)

31. Mao R, Wang X, Shi R (2017) Classification of edible vegetable oils and discrimination of catering waste oils by LF-NMR combined with chemometrics method. J Instrum Anal 36(3):372376. https://doi.org/10.3969/j.issn.1004-4957.2017.03.013 (in Chinese)

32. MOA (2004) Performance ferms and measurement for poultry. China Standards Press, Beijing, $\mathrm{p} 10$

33. MOA (2009) Fresh egg grading. China Standards Press, Beijing

34. Moba (2019) Forta gt 100 machine for grading and packing eggs. Retrieved from https://www.moba.net/page/cn/Products/Detai I/forta/1535

35. NHFPC (2015) National food safety standard-egg and egg products. China Standards Press, Beijing

36. Sanchez-Alonso I, Martinez I, Sanchez-Valencia J, Careche M (2012) Estimation of freezing storage time and quality changes in hake (Merluccius merluccius L.) by low field NMR. Food Chem 135(3):1626-1634. https://doi.org/10.1016/j.foodc hem.2012.06.038

37. Sanovo (2019) Features of optigrader. Retrieved from https:// www.sanovogroup.com/products/egg-grading/grading/optig rader/features/

38. Scott TA, Silversides FG (2000) The effect of storage and strain of hen on egg quality. Poult Sci 79(12):1725-1729. https://doi. org/10.1093/ps/79.12.1725

39. Shao JH, Deng YM, Jia N, Li RR, Cao JX et al (2016) Low-field NMR determination of water distribution in meat batters with $\mathrm{NaCl}$ and polyphosphate addition. Food Chem 200:308-314. https:// doi.org/10.1016/j.foodchem.2016.01.013

40. Silversides F, Villeneuve $P(1994)$ Is the Haugh unit correction for egg weight valid for eggs stored at room temperature? Poult Sci 73:50-55. https://doi.org/10.3382/ps.0730050

41. Silversides FG, Budgell K (2004) The relationships among measures of egg albumen height, $\mathrm{pH}$, and whipping volume. Poult Sci 83(10):1619-1623. https://doi.org/10.1093/ps/83.10.1619 
42. Soltani M, Omid M (2015) Detection of poultry egg freshness by dielectric spectroscopy and machine learning techniques. LWT Food Sci Technol 62(2):1034-1042. https://doi.org/10.1016/j. Iwt.2015.02.019

43. Soltani M, Omid M, Alimardani R (2015) Egg quality prediction using dielectric and visual properties based on artificial neural network. Food Anal Methods 8(3):710-717. https://doi. org/10.1007/s12161-014-9948-x

44. Stadelman WJ, Cotterill OJ (2007) Egg science and technology. 4th, Edition edn. Haworth Press Inc., New York

45. Su HP, Lin C-W (1993) A new process for preparing transparent alkalised duck egg and its quality. J Sci Food Agric 61:117-120. https://doi.org/10.1002/jsfa.2740610118

46. Suktanarak S, Teerachaichayut S (2017) Non-destructive quality assessment of hens' eggs using hyperspectral images. J Food Eng 215:97-103. https://doi.org/10.1016/j.jfoodeng.2017.07.008

47. Sun B, Zhao H, Feng X, Huang X, Wang N (2016) Studies on the change of moisture state of fresh jujube during storage base on LF-NMR and MRI. J Chin Inst Food Sci Technol 16(5):252-257. https://doi.org/10.16429/j.1009-7848.2016.05.035

48. Sun J, Liu B, Mao H, Wu X, Gao H et al (2016) Non-destructive examination for freshness of eggs based on dielectric properties and yolk index regression model. Nongye Gongcheng Xuebao/Trans Chin Soc Agric Eng 32(21):290-295. https://doi. org/10.11975/j.issn.1002-6819.2016.21.040 (in Chinese)

49. Tan MQ, Lin ZY, Zu YX, Zhu BW, Cheng SS (2018) Effect of multiple freeze-thaw cycles on the quality of instant sea cucumber: emphatically on water status of by LF-NMR and MRI. Food Res Int 109:65-71. https://doi.org/10.1016/j.foodres.2018.04.029
50. UNECE (2017) Egg-1 UNECE standard eggs-in-shell. United Nations, New York, p 16

51. Wang YF, Liu LZ, Gong ZY, Fang MJFS (2008) Study on application of chlorine dioxide treatment in disinfection and fresh-keeping of shell eggs. Food Sci 29(11):632-636. https://doi.org/10.3321/j. issn:1002-6630.2008.11.149 (in Chinese)

52. Xu L, Jia F, Luo CY, Zhao FH, Gao F et al (2017) Using LF-NMR to study the changes of moisture content of egg white under carbon dioxide modified atmosphere storage. Sci Technol Food Ind 38(2):313-318. https://doi.org/10.13386/j.issn10020306.2017.02.052 (in Chinese)

53. Zhang W, Pan LQ, Tu SC, Zhan G, Tu K (2015) Non-destructive internal quality assessment of eggs using a synthesis of hyperspectral imaging and multivariate analysis. J Food Eng 157:4148. https://doi.org/10.1016/j.jfoodeng.2015.02.013

54. Zhang WJ, Xue CH, Cong HH, Jia M, Wang ZQ (2012) Study on the change of moisture state in sea cucumber during rehydration processing by LF-NMR and LF-MRI. Sci Technol Food Ind 33(23):90-93. https://doi.org/10.13386/j.issn10020306.2012.23.077 (in Chinese)

Publisher's Note Springer Nature remains neutral with regard to jurisdictional claims in published maps and institutional affiliations. 